\title{
Does the uptake of wagering inducements predict impulse betting on sport?
}

\author{
NERILEE HING ${ }^{1}$, ALEX M. T. RUSSELL ${ }^{2}$, EN LI $^{3}$ and PETER VITARTAS ${ }^{4}$ \\ ${ }^{1}$ School of Health, Medical and Applied Sciences, Central Queensland University, Bundaberg, QLD, Australia \\ ${ }^{2}$ School of Health, Medical and Applied Sciences, Central Queensland University, Sydney, NSW, Australia \\ ${ }^{3}$ School of Business and Law, Central Queensland University, North Rockhampton, QLD, Australia \\ ${ }^{4}$ La Trobe Business School, La Trobe University, Bundoora, VIC, Australia
}

(Received: October 10, 2017; revised manuscript received: December 13, 2017; accepted: February 4, 2018)

\begin{abstract}
Background and aims: Marketing inducements for addictive products, such as wagering, can prompt impulse purchasing by triggering consumption reminders, urges, and cravings. Wagering inducements incentivize betting by providing bonus bets, money-back guarantees, deposits into betting accounts, and discounts. Their promotion during sporting events, push marketing efforts directed at consumers, and ease of uptake at the point-of-sale, may trigger betting on impulse. This study examined whether the uptake of wagering inducements predicted impulse betting on sport. Methods: Australian sports bettors $(N=1,813)$ completed an online survey measuring their proportion of planned bets, impulse bets before match commencement, and impulse bets during play; frequency of using wagering inducements; and several psychological, behavioral, and demographic variables. Results: More frequent users of wagering inducements had a greater tendency to place impulse in-play bets, which were also predicted by problem gambling, higher buying impulsiveness, higher frequency of watching sports, younger age, and higher educational status. Sports bettors with a greater tendency to place impulse bets before match commencement also tended to have higher buying impulsiveness and to be younger, but they used inducements less frequently, and tended to be female, less-educated and non-problem, moderate risk, or problem gamblers. Discussion and conclusions: Uptake of wagering inducements appeared to be particularly effective in stimulating impulse in-play betting among problem gamblers and frequent sports viewers. These results suggest that a more cautious approach to the regulation of both in-play bets and wagering inducements may be required to better protect young adults from gambling problems and harm.
\end{abstract}

Keywords: sports betting, inducements, sales promotions, marketing, live-action betting, problem gambling

\section{INTRODUCTION}

Sports betting is one of the most heavily promoted gambling forms in many countries. Research has examined several aspects of sports-betting advertising, including its overt and latent content (Lopez-Gonzalez, Estévez, \& Griffiths, 2017a, 2017b; Lopez-Gonzalez, Guerrero-Solé, Estévez, \& Griffiths, 2017; Lopez-Gonzalez, Guerrero-Solé, \& Griffiths, 2017; Milner, Hing, Vitartas, \& Lamont, 2013; Sproston, Hanley, Brook, Hing, \& Gainsbury, 2015); the persuasive appeal of different message attributes (Hing, Vitartas, \& Lamont, 2017); impacts on problem gamblers and minors (Hing, Russell, Vitartas, \& Lamont, 2016; Hing, Vitartas, Lamont, \& Fink, 2014; Lopez-Gonzalez et al., 2017a; Lopez-Gonzalez \& Griffiths, 2017b; Sproston et al., 2015); and its role in normalizing the activity (LopezGonzalez et al., 2017a; Lopez-Gonzalez, Guerrero-Solé, et al., 2017; Sproston et al., 2015).

Although sports-betting advertising occurs through diverse media and may promote the brand or specific product features, opportunities to bet are often promoted and incentivized with wagering inducements (Guerrero-Solé, LopezGonzalez, \& Griffiths, 2017; Hing, Sproston, Brading, \&
Brook, 2015; Lopez-Gonzalez \& Griffiths, 2017a, 2017b). Wagering inducements have been described as (a) being typically presented as sales promotions, (b) offering one or more incentives to bet in addition to what is normally received by the core-wagering product, (c) where the incentive is offered in conjunction with a specified betting-related activity and/or redeemed in a form that encourages betting, and (d) that aim to lead to additional sales (Hing et al., 2015). Wagering inducements attempt to increase sales through increasing the number of account holders, retaining existing account holders, prompting brand switching, increasing and intensifying purchasing, encouraging future purchasing, and stimulating betting on specific events, during particular time periods, and/or using particular betting channels, such as mobile platforms (Hing et al., 2015).

A recent review of wagering inducements identified 15 generic types, with the most prominent being stake-back offers, sign-up offers, bonus or better odds, bonus or better

* Corresponding author: Nerilee Hing; School of Health, Medical and Applied Sciences, Central Queensland University, University Drive, Bundaberg, QLD 4670, Australia; Phone: +617 4150 7700; Fax: +61 74150 7080; E-mail: n.hing@cqu.edu.au

This is an open-access article distributed under the terms of the Creative Commons Attribution-NonCommercial 4.0 International License, which permits unrestricted use, distribution, and reproduction in any medium for non-commercial purposes, provided the original author and source are credited, a link to the CC License is provided, and changes - if any - are indicated. 
winnings, multibet offers, matching stakes and deposits, happy hours, cash rebates, and refer-a-friend offers (Hing, Sproston, Brook, \& Brading, 2017). Bonus bets, money-back guarantees, deposits into betting accounts, and discounts are typical incentives accompanying these promotions, offering consumers something for "free" - but usually only if a new customer opens a betting account or the incentivized bet wins (Danson, 2010; Lopez-Gonzalez \& Griffiths, 2017b). Furthermore, the most heavily promoted inducements have been criticized for offering complex bets with poor odds of winning, which yield high operator profit margins, and for being framed in ways that are likely to mislead consumers (Newall, 2015, 2017). New types of wagering inducements continue to be introduced, such as the cash-out option, which transforms sports betting into a continuous activity, and facilitates loss of control due to its structural characteristics and the emotionally charged context in which it is typically used (Lopez-Gonzalez \& Griffiths, 2017a). Wagering inducements are widely marketed on websites, mobile-betting apps, and in social media; through broadcast, print, and retail advertisements; and through promotions during live and broadcast sporting events and sports entertainment shows (Hing, Lamont, Vitartas, \& Fink, 2015a; Lopez-Gonzalez \& Griffiths, 2017b; Newall, 2015).

Marketing cues for addictive products can prompt a variety of consumer responses, including product trial, and continuation and intensification of consumption, facilitating an individual's movement from non-use through non-addictive use to near-addictive use to addiction (Martin et al., 2013). Gambling advertising and promotion are known to trigger consumption, especially among at-risk and problem gamblers, through providing reminders to bet and by activating urges and craving (Binde, 2014; Hing, Cherney, Blaszczynski, Gainsbury, \& Lubman, 2014; Lopez-Gonzalez et al., 2017a). A large Norwegian study $(N=6,034)$ found that 57 problem gamblers in the sample were more likely to report that gambling advertising impacted on their gambling-related attitudes, interest, and behavior compared with recreational gamblers, independent of level of exposure to this advertising (Hanss, Mentzoni, Griffiths, \& Pallesen, 2015). Other research has noted the role of key narratives in sports-betting advertising in enhancing illusions of control and lowering the perceived risk of betting, which may foster problem gambling (LopezGonzalez et al., 2017a, 2017b; Lopez-Gonzalez, GuerreroSolé, Estévez, et al., 2017).

Because gambling inducements also provide financial incentives to purchase, they may provide particularly powerful and immediate purchasing cues for impulse betting. Drawing on broader conceptualizations of impulsiveness and impulse purchasing, Hing, Li, Vitartas, and Russell (2017) defined impulse betting as unplanned, spontaneous betting without much deliberate or thoughtful consideration of why the bet should be placed and of its likely outcomes and consequences. In recognition that impulse betting undermines responsible consumption of gambling and may contribute to gambling problems and harm, Hing, Li, et al. (2017) called for research into whether wagering inducements stimulate impulsive betting responses. Such research appears warranted, given several aspects of wagering inducements are likely to prompt instantaneous, unplanned, and unreflective purchasing.

\section{Wagering inducements and impulse betting}

Wagering inducements may prompt impulse betting, because they are offered at the point-of-sale (on betting websites and on mobile apps) where consumers have an immediate opportunity to place the incentivized bet through these platforms. This may result in cue-related impulsive responses, as found for point-of-sale tobacco and alcohol advertising. An Australian intercept survey of 206 smokers found that point-of-sale cigarette displays stimulated nearly four times as many unplanned as planned purchases (Carter, Mills, \& Donovan, 2009). A retrospective Australian study found that seeing a cigarette display resulted in $25.2 \%$ of smokers buying cigarettes on impulse, and $33.9 \%$ of recent quitters experiencing buying urges (Wakefield, Germain, \& Henriksen, 2008). In a US study, which tracked 475 participants daily during their first month of a smoking-quit attempt, lapsing was significantly more likely on days with a point-of-sale tobacco contact, and increased significantly with the number of contacts (Kirchner et al., 2013). These studies demonstrate the powerful effect of point-of-sale promotion, but only in relation to addicted consumers. Nonetheless, alcohol research suggests that point-of-sale promotion can also prompt impulse purchasing among non-addicted consumers. Many purchases made by young people in response to bottle shop promotions are reportedly impulsive, particularly price- and volume-related promotions, affecting the type, range, and quantity of alcohol purchased and consumed (Jones \& Smith, 2011; Pettigrew et al., 2015).

A further reason why wagering inducements may stimulate impulse betting is that they are directly marketed to consumers through direct e-mails, text messages, phone calls, and being embedded in social media feeds, making them difficult to avoid - in the same way that point-of-sales displays are highly visible, difficult to circumvent and therefore encourage impulse buying of other addictive products (Carter et al., 2009; Pettigrew et al., 2015). Push marketing activity is potentially effective in triggering impulse buying (Unni \& Harmon, 2007), because the medium enables consumers to immediately respond and receive instant gratification and need fulfillment (Kannan, Chang, \& Whinston, 2001). Young adults are both a risk group for problem gambling (Calado \& Griffiths, 2016) and have high usage of mobile phones (Lopez-Fernandez et al., 2017). This may increase their likelihood of receiving push marketing messages from sports-betting operators and of an impulsive response. However, consumer responses to push marketing activities vary, with the tendency to purchase impulsively found to vary with generalized impulse buying tendency and level of product involvement (Drossos, Kokkinaki, Giaglis, \& Fouskas, 2014). Some research points to increased impulse gambling among problem Internet gamblers, including lapsed problem gamblers in treatment, in response to push marketing efforts from gambling operators (Hing, Cherney, et al., 2014).

Wagering inducements might also prompt impulse betting, because consumers can easily and instantaneously respond by clicking on a link in the inducement message within the operator's website, mobile app, direct e-mail, SMS, or social media feed to the bettor. Ease of purchasing is a critical factor explaining why online shoppers buy more 
impulsively than offline shoppers, with sales promotions being one of the strongest triggers for impulse purchasing online (Dawson \& Kim, 2010; Jeffrey \& Hodge, 2007; Koski, 2004). Price discounts are particularly effective in prompting impulse buying online, especially for inexpensive hedonic products, such as gambling (Xu \& Huang, 2014). Among young adults, online gamblers are more likely to initiate gambling to make money, compared with offline gamblers (Goldstein, Vilhena-Churchill, Stewart, Hoaken, \& Flett, 2016). Wagering on promoted bets, which provide financial inducements in the form of price discounts, bonuses, reduced financial risk, or extra betting money may be similarly facilitated by their easy online access (Griffiths, 2007; Hing, Sproston, et al., 2017).

Wagering inducements may also prompt impulsive betting, because they are heavily promoted during the broadcast and live sporting events themselves and may therefore encourage in-play betting. An analysis of British and Spanish television advertisements for sports betting found that in-play betting was depicted in nearly one half of the 135 advertisements examined (Lopez-Gonzalez, GuerreroSole, et al., 2017). In-play betting refers to bets placed during the course of a sporting event, after the event has commenced. Some types of bets can be placed both in-play and before event commencement (e.g., on the outcome of the match; on key events within the match, such as which team will kick the first goal), whereas others can only be placed after match commencement as they are dependent on in-match contingencies as they unfold (e.g., micro bets on the outcome of the next ball in cricket or the next point in tennis; Milner et al., 2013). Regardless of bet type, inducements promoted during an event and related to that specific event are time-sensitive and therefore likely to invoke a sense of urgency about making the bet. Micro bets are particularly time-sensitive, with bettors typically having less than $5 \mathrm{~min}$ to place the bet. These conditions are highly conducive to betting on impulse in response to an inducement promoted during the event, as self-reported by about one quarter of participants in a survey of 544 Australian sports bettors (Hing, Lamont, Vitartas, \& Fink, 2015b). Participants in a qualitative study also indicated that inmatch promotions for in-play bets stimulated impulse betting intentions (Lamont, Hing, \& Vitartas, 2016). Furthermore, the availability of in-play bets per se has aroused concerns for their potential to prompt impulse betting (Hing, Sproston, et al., 2017; Lopez-Gonzalez \& Griffiths, 2016, 2017a).

Based on the aspects of wagering inducements discussed above, this study aimed to examine whether uptake of wagering inducements predicts impulse betting on sport. We hypothesized that more frequent users of wagering inducements tend to bet more impulsively.

\section{METHODS}

\section{Design}

The analyses in this paper are an extension of previous work conducted by the authors (Hing, Li, et al., 2017). Utilizing the same data set, they examined behavioral, psychological, and sociodemographic predictors of impulse sports betting to help address a gap in knowledge about intrinsic influences on impulse betting. In contrast, the current analyses focus on the extrinsic influence of wagering inducements to examine whether their uptake also predicts impulse betting on sport. Given that Hing, Li, et al. (2017) found several significant intrinsic predictors in their previous work, similar measures of those predictors were included as control variables in the current analyses, as described below.

\section{Recruitment, participants, and procedure}

A total of 1,813 respondents were recruited to an online survey through a panel provider (Qualtrics, Sydney office) between July and September 2016. Inclusion criteria were aged at least 18 years, living in Australia, and having bet on sports in the previous 12 months. Median survey completion time was $17.0 \mathrm{~min}$ and respondents were compensated for participation according to the panel provider's internal protocols.

Gaining a random sample of Australian sports bettors was not possible due to cost considerations, and we also wanted to ensure sufficient numbers of respondents at varying levels of problem gambling severity, as this likely impacts on any role of inducements in prompting impulse betting. We therefore aimed to reasonably recruit equal proportions who bet on sports more than once a week (21.0\%), weekly (19.7\%), 2-3 times a month (17.0\%), monthly (18.5\%), and less than once a month (23.9\%), with the proportions in the final sample shown in brackets. This sampling strategy yielded surprisingly large numbers of problem gamblers $(46.8 \%)$, with $17.6 \%$ being moderaterisk gamblers, $16.2 \%$ low-risk gamblers, and $19.5 \%$ nonproblem gamblers (Table 1).

Table 1 indicates that the sample was mostly male $(68.9 \%)$, with a mean age of 35.3 years $(S D=12.7$ years); and the majority were married or in a de facto relationship $(60.4 \%)$ and had some post-secondary school education (66.4\%). The typical sports bettor in this study had an annual personal net income between AU\$50,000-59,999 and a weekly disposable income between AU\$151-200. Overall, our sample was consistent with the young male partnered profile of sports bettors in Australia; however, problem gamblers and those in lower income brackets were overrepresented in our sample (Hing, Gainsbury, et al., 2014).

\section{MEASURES}

\section{Dependent variables}

The three dependent variables for analyses were derived from a question asking the percentage of the respondent's past-year sports bets that were "researched and planned in advance of the match," "on impulse before the start of the match," and "on impulse during the match." The instructions explained that "an impulse bet is one which is unplanned, spontaneous, and placed without much thoughtful consideration." Responses were required to sum to $100 \%$. The three dependent variables aligned with these three categories of responses. 
Table 1. Mean (and $S D$ ) percentage of sports bets that were planned, or that were placed on impulse before or during the match, by demographic and problem gambling categories

\begin{tabular}{|c|c|c|c|c|}
\hline Variable & $\%$ planned & $\begin{array}{l}\% \text { impulse before } \\
\text { match }\end{array}$ & $\begin{array}{l}\% \text { impulse during } \\
\text { match }\end{array}$ & $\begin{array}{l}\text { Sample characteristics } \\
\text { (\% of sample in each category) }\end{array}$ \\
\hline \multicolumn{5}{|l|}{ Gender } \\
\hline Male & $58.98(35.33)$ & $29.85(31.02)$ & $11.36(18.84)$ & 68.9 \\
\hline Female & $41.24(33.63)$ & $44.50(34.16)$ & $14.34(18.68)$ & 31.1 \\
\hline Inferential statistics & $\begin{array}{c}F(1,1809)=100.74 \\
p<.001\end{array}$ & $\begin{array}{c}F(1,1807)=81.09 \\
p<.001\end{array}$ & $\begin{array}{c}F(1,1809)=9.77 \\
p=.002\end{array}$ & \\
\hline \multicolumn{5}{|l|}{ Marital status } \\
\hline Single/never married & $53.32(36.40)$ & $34.26(33.49)$ & $12.64(20.82)^{\mathrm{a}}$ & 33.7 \\
\hline De facto & $50.72(38.68)$ & $39.58(36.79)$ & $10.11(18.38)^{\mathrm{a}, \mathrm{b}}$ & 17.4 \\
\hline Married & $53.61(33.45)$ & $32.71(29.67)$ & $13.70(17.71)^{\mathrm{a}}$ & 43.0 \\
\hline $\begin{array}{l}\text { Divorced/separated/ } \\
\text { widowed }\end{array}$ & $61.28(38.67)$ & $32.40(35.90)$ & $6.32(14.06)^{\mathrm{b}}$ & 5.9 \\
\hline Inferential statistics & $\begin{array}{c}F(3,1807)=2.33 \\
p=.072\end{array}$ & $\begin{array}{c}F(3,1805)=3.45 \\
p=.016^{\#}\end{array}$ & $\begin{array}{c}F(3,1807)=6.59 \\
p<.001\end{array}$ & \\
\hline \multicolumn{5}{|l|}{ Education } \\
\hline $\begin{array}{l}\text { Did not complete high } \\
\text { school }\end{array}$ & $50.17(39.08)$ & $42.48(36.76)^{\mathrm{b}}$ & $8.14(18.45)^{\mathrm{a}}$ & 9.9 \\
\hline Year 12 or equivalent & $53.10(36.19)$ & $34.68(32.50)^{\mathrm{a}}$ & $12.30(18.05)^{\mathrm{a}, \mathrm{b}}$ & 23.7 \\
\hline $\begin{array}{l}\text { Trade, technical } \\
\text { certificate, or diploma }\end{array}$ & $56.24(36.32)$ & $34.44(34.00)^{\mathrm{a}}$ & $9.40(17.11)^{\mathrm{a}}$ & 24.6 \\
\hline $\begin{array}{l}\text { University or college } \\
\text { degree }\end{array}$ & $51.59(33.95)$ & $33.25(30.31)^{\mathrm{a}}$ & $15.28(20.20)^{\mathrm{b}}$ & 31.8 \\
\hline Postgraduate qualifications & $56.67(35.25)$ & $29.33(29.82)^{\mathrm{a}}$ & $14.00(18.98)^{\mathrm{b}}$ & 10.0 \\
\hline Inferential statistics & $\begin{array}{c}F(4,1806)=1.82 \\
p=.122\end{array}$ & $\begin{array}{c}F(4,1804)=4.04 \\
p=.003\end{array}$ & $\begin{array}{c}F(4,1806)=8.95 \\
p<.001\end{array}$ & \\
\hline \multicolumn{5}{|c|}{ 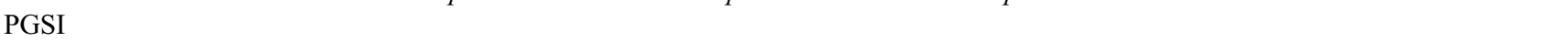 } \\
\hline Non-problem & $59.47(40.84)^{\mathrm{b}}$ & $37.24(40.31)^{\mathrm{a}}$ & $3.56(11.40)^{\mathrm{a}}$ & 19.5 \\
\hline Low risk & $67.13(36.92)^{\mathrm{a}}$ & $27.98(33.58)^{b}$ & $4.89(13.17)^{\mathrm{a}, \mathrm{b}}$ & 16.2 \\
\hline Moderate risk & $58.36(35.51)^{\mathrm{b}}$ & $34.62(33.69)^{\mathrm{a}}$ & $7.26(14.57)^{\mathrm{b}}$ & 17.6 \\
\hline Problem gambler & $44.39(30.47)^{\mathrm{c}}$ & $35.36(27.99)^{\mathrm{a}}$ & $20.37(20.97)^{\mathrm{c}}$ & 46.8 \\
\hline Inferential statistics & $\begin{array}{c}F(3,1807)=40.18 \\
p<.001\end{array}$ & $\begin{array}{c}F(3,1805)=4.93 \\
p=.002\end{array}$ & $\begin{array}{c}F(3,1807)=119.46 \\
p<.001\end{array}$ & \\
\hline
\end{tabular}

Note. Sample descriptive statistics included. Letters ( $\mathrm{a}, \mathrm{b}$, and $\mathrm{c}$ ) in superscript indicate significant pairwise differences between groups per sports-betting variable. Groups with the same letters do not significantly differ, whereas the groups that have two letters (e.g., a, b) do not significantly differ from any group with either of those letters. Tests are one-way ANOVA with pairwise Tukey's tests. $S D$ : standard deviation; PGSI: Problem Gambling Severity Index.

"Pairwise comparisons found no significant differences, despite a significant omnibus ANOVA.

\section{Independent variables}

While frequency of using sports-betting inducements was the main independent variable of interest, several others were included as control variables. Previous analysis using the current data set found that trait impulsivity, problem gambling severity, number of sports-betting days per month, age, gender, and highest educational level are associated with either more impulsive or more planned betting (Hing, Li, et al., 2017). Thus, similar measures were included in the testing of our hypothesis. To obtain proxy measures of exposure to sports-betting advertising, we included questions about frequency of sports watching (as sports-betting inducements are often promoted during live and broadcast events), and of exposure to sports-betting advertising and promotions more generally, as explained further below.

Use of sports-betting inducements. The respondents were asked to indicate how often they had taken up each of 10 promotions (inducements) during the past 12 months (Table 2). As these variables were highly correlated
(Pearson's $r=\sim .7$ ), we could not enter them all into a regression together. Therefore, a summary variable was calculated by averaging the frequency of use of the 10 inducements during the past 12 months (Cronbach's $\alpha=.96)$.

Sports watching and exposure to advertising and promotions. The respondents were asked how frequently they watched each of nine sports live, on television, or online during the most recent or current season. The most popular betting sports in Australia were chosen: Rugby League, Australian rules football, Rugby Union, soccer (football), cricket, motor racing, golf, tennis, and basketball. These variables were correlated and thus averaged into a composite variable (Cronbach's $\alpha=.86$ ). The respondents were also asked how often they saw or heard advertisements and promotions for sports betting when exposed to the media (never, sometimes, most of the time, and almost always).

Sports-betting frequency. The respondents were asked their frequency of sports betting during the past 12 months (never, less than once every 2 months, about once every 
Table 2. Pearson's correlations between each of the three dependent variables (percentage of bets planned in advance, placed on impulse before the match, and placed on impulse during the match) and continuous independent variables

\begin{tabular}{lccc}
\hline Variable & \% planned in advance & $\%$ impulse before match & $\%$ impulse during match \\
\hline Age (years) & $0.16^{* *}$ & $-0.10^{* *}$ & $-0.18^{* *}$ \\
Personal annual pretax income & -0.04 & 0.00 & $0.18^{* *}$ \\
Weekly disposable income & -0.01 & -0.01 & $0.09^{* *}$ \\
Sports-betting frequency & 0.01 & -0.03 & $0.24^{* *}$ \\
Sports-watching frequency & $-0.07^{*}$ & -0.02 & $0.44^{* *}$ \\
Exposure to sports-betting marketing & $0.09^{* *}$ & $-0.06^{*}$ & $-0.10^{* *}$ \\
Use of inducements & & & $0.43^{* *}$ \\
Sign-up offer & $-0.20^{* *}$ & -0.03 & $0.46^{* *}$ \\
Refer-a-friend offer & $-0.21^{* *}$ & -0.04 & $0.39^{* *}$ \\
Mobile-betting offer & $-0.19^{* *}$ & -0.02 & $0.45^{* *}$ \\
Click-to-call bonus & $-0.18^{* *}$ & $-0.06^{*}$ & $0.35^{* *}$ \\
Multibet offer & $-0.13^{* *}$ & $-0.06^{*}$ & $0.33^{* *}$ \\
Refund/stake-back offer & $-0.11^{* *}$ & $-0.07^{*}$ & $0.35^{* *}$ \\
Match your stake or deposit & $-0.13^{* *}$ & $-0.06^{*}$ & $0.35^{* *}$ \\
Bonus or better odds or winnings & $-0.14^{* *}$ & -0.04 & $0.36^{* *}$ \\
Happy hour & $-0.16^{* *}$ & -0.03 & $0.37^{* *}$ \\
Offer of operator credit & $-0.16^{* *}$ & -0.03 & $0.45^{* *}$ \\
Average frequency of inducements used & $-0.19^{* *}$ & $-0.05^{*}$ & $0.32^{* *}$ \\
Buying impulsiveness & $-0.32^{* *}$ & $0.25^{* *}$ & \\
\hline
\end{tabular}

Note. ${ }^{*} p<.05 .{ }^{*} p<.001$.

2 months, about once a month, 2-3 times a month, about once a week, 2-3 times a week, and 4 times or more a week).

Buying Impulsiveness Scale (Rook \& Fisher, 1995). This nine-item scale was originally developed through exploratory factor analysis, correlational tests, and confirmatory factor analysis based on 35 items derived from a literature review of impulse buying phenomenology and of general measures of impulsiveness. Response options ranged from "strongly disagree" (1) to "strongly agree" (5). Cronbach's $\alpha$ in the current sample was .87 .

Problem Gambling Severity Index (PGSI; Ferris \& Wynne, 2001). The nine questions in the PGSI were asked, with response options ranging from "never" (0) to "almost always" (3). Responses were summed across the items, with possible scores ranging from 0 to 27 . Based on these scores, respondents were classified into non-problem gambler $(0)$, low-risk gambler (1-2), moderate-risk gambler (3-7), and problem gambler (8-27). Cronbach's $\alpha$ for the PGSI in this sample was 94 .

Demographics. Gender (male and female), age (in years), personal pretax annual income (in brackets), and disposable weekly income (in brackets) were collected. The respondents also provided their marital status and highest completed level of education (Table 1). For marital status, only nine respondents reported being widowed, and they were thus recoded into the same category as divorced or separated respondents.

\section{Statistical analysis}

Two of the three dependent variables (impulse bets before or during the match) were skewed, so we explored alternate analyses, such as log transformations and alternative distributions. The results were similar to those obtained through regular linear regression, and we therefore opted to use a consistent type of analysis for all variables. Furthermore, using non-transformed variables allowed us to report means and standard deviations of percentages, rather than transformed percentages, which are not immediately interpretable.

Independent variables were first assessed using bivariate analyses, using one-way analysis of variance (ANOVA) for categorical variables, or correlations for continuous variables. To account for any possible overlap between independent variables, three multiple linear regressions were conducted, one for each dependent variable. All independent variables were entered into each model and tested for multicollinearity by examining tolerance statistics. Tolerance for the individual inducements was low, because they were correlated with each other $(r=\sim .7)$. Thus, they were removed from the model and replaced by the average frequency of use of inducements (described in independent variables above). No further issues with multicollinearity were detected.

Each dependent variable had a small amount of missing data (2-4 respondents per variable), and these respondents were removed from each relevant analysis. Data were also missing for the annual income question as it was optional (due to its potential sensitivity), and these 89 respondents were not included in any analysis where annual income was included. Unless stated otherwise, an $\alpha$ of .05 was used throughout.

\section{Ethics}

The study procedures were carried out in accordance with the Declaration of Helsinki. The institutional review board of Central Queensland University Human Research Ethics Committee approved the study. All subjects were informed about the study and all provided informed consent. 


\section{RESULTS}

\section{Bivariate results}

Table 1 presents the descriptive results for the categorical data and ANOVAs for each of the three dependent variables. Table 2 presents the correlations between each of the three dependent variables and continuous independent variables.

Factors related to a higher \% of bets researched and planned in advance of the match. On average, respondents reported that $53.46 \%(S D=35.76)$ of their bets were researched and planned in advance. The following factors were significantly related to a higher proportion of bets researched and planned in advance of the match: being male, not being a problem gambler or being a low-risk gambler, being older, watching sports less frequently, more frequent exposure to gambling-related marketing when exposed to the media, less frequent use of each of the 10 inducements surveyed, less-frequent average use of inducements, and lower buying impulsiveness.

Factors related to a higher percentage of bets placed on impulse before the start of the match. On average, respondents reported that $34.40 \%(S D=32.73)$ of their bets were placed on impulse before the start of the match. The following factors were significantly related to a higher proportion of bets placed on impulse before the start of the match: being female, lower levels of education (specifically not completing high school), PGSI levels other than lowrisk gamblers, younger age, less exposure to gamblingrelated marketing when exposed to the media, and higher buying impulsiveness. However, all correlations apart from impulsiveness are relatively small $(|r|=\sim .1)$ and may only be significant because of the large sample size; thus, we interpret them with caution.

Factors related to a higher percentage of bets placed on impulse during the match. On average, respondents reported that $12.29 \%(S D=18.83 \%)$ of their bets were placed on impulse during the match. The following factors were significantly related to a higher proportion of bets placed on impulse during the match: being female, being single/ never married or married, higher levels of education (particularly those with undergraduate or postgraduate qualifications), higher PGSI levels (particularly moderate risk or problem gamblers), younger age, higher personal and disposable income, more frequent sports betting and sports watching, less exposure to marketing when exposed to the media, and higher buying impulsiveness. Higher frequency of using all 10 surveyed inducements was related to a higher proportion of bets placed on impulse during the match, as was more frequent average use of inducements.

\section{Multivariate results}

Separate multiple linear regressions were conducted for each of the three dependent variables. The independent variables entered into each model were based on significant factors in the bivariate analyses. As noted earlier, the variables capturing use of each of the 10 inducements were highly correlated, causing multicollinearity issues in the model. Instead, we entered average frequency of using the inducements into each model.

Factors related to a higher percentage of bets researched and planned in advance of the match. $R^{2}$ for the overall model was $.17,[F(9,1800)=40.66, p<.001]$. The following predictors were statistically significant when controlling for all other variables in the model: being male, being older, being a low-risk gambler (compared with nonproblem gamblers), and lower levels of buying impulsiveness. Variables that were no longer statistically significant in the multivariate analyses were sports-watching frequency, frequency of exposure to marketing when exposed to the media, and average frequency of using inducements used (Table 3).

Factors related to a higher percentage of bets placed on impulse before the start of the match. $R^{2}$ for the overall model was $.11,[F(15,1792)=15.40, p<.001]$. The following predictors were statistically significant when controlling for all other variables in the model: being female, being younger, being less educated, being anything other than a low-risk gambler on the PGSI, less-frequent use of inducements, and higher buying impulsiveness (Table 4).

Factors related to a higher percentage of bets placed on impulse during the match. $R^{2}$ for the overall model was .25 ,

Table 3. Regression coefficients predicting percentage of bets that were researched and planned in advance of the match

\begin{tabular}{|c|c|c|c|c|c|c|c|}
\hline \multirow[b]{2}{*}{ Predictor } & \multirow[b]{2}{*}{ Unstd. coeff. } & \multirow[b]{2}{*}{$S E$} & \multicolumn{2}{|c|}{$95 \% \mathrm{CI}$} & \multirow[b]{2}{*}{ Std. coeff. } & \multirow[b]{2}{*}{$t$} & \multirow[b]{2}{*}{$p$} \\
\hline & & & LL & UL & & & \\
\hline Intercept & 85.51 & 5.41 & 74.90 & 96.11 & & 15.81 & $<.001$ \\
\hline Gender (ref.: male) & -12.88 & 1.72 & -16.25 & -9.50 & -0.17 & -7.48 & $<.001$ \\
\hline Age (years) & 0.28 & 0.07 & 0.15 & 0.41 & 0.10 & 4.20 & $<.001$ \\
\hline \multicolumn{8}{|l|}{ PGSI groups (ref.: non-problem) } \\
\hline Low risk & 8.47 & 2.61 & 3.35 & 13.59 & 0.09 & 3.24 & .001 \\
\hline Moderate risk & 1.58 & 2.62 & -3.56 & 6.72 & 0.02 & 0.60 & .547 \\
\hline Problem & -4.70 & 2.72 & -10.02 & 0.63 & -0.07 & -1.73 & .084 \\
\hline Sports-watching frequency & 1.30 & 0.81 & -0.30 & 2.89 & 0.05 & 1.59 & .112 \\
\hline Exposure to marketing & 1.82 & 0.99 & -0.13 & 3.77 & 0.04 & 1.83 & .068 \\
\hline Average frequency of inducements used & -0.10 & 0.53 & -1.14 & 0.95 & -0.01 & -0.19 & .852 \\
\hline Buying impulsiveness & -10.98 & 1.13 & -13.18 & -8.77 & -0.25 & -9.76 & $<.001$ \\
\hline
\end{tabular}

Note. Significant predictors are represented in bold. Unstd. coeff.: unstandardized coefficient; Std. coeff.: standardized coefficient; $S E$ : standard error; CI: confidence interval; LL: lower limit; UL: upper limit; PGSI: Problem Gambling Severity Index.

$R^{2}=.17,[F(9,1800)=40.66, p<.001]$. 
Table 4. Regression coefficients predicting percentage of bets that were placed on impulse before the start of the match

\begin{tabular}{|c|c|c|c|c|c|c|c|}
\hline \multirow[b]{2}{*}{ Predictor } & \multirow[b]{2}{*}{ Unstd. coeff. } & \multirow[b]{2}{*}{$S E$} & \multicolumn{2}{|c|}{$95 \% \mathrm{CI}$} & \multirow[b]{2}{*}{ Std. coeff. } & \multirow[b]{2}{*}{$t$} & \multirow[b]{2}{*}{$p$} \\
\hline & & & LL & UL & & & \\
\hline Intercept & 23.79 & 6.25 & 11.54 & 36.04 & & 3.81 & $<.001$ \\
\hline Gender (ref.: male) & 12.12 & 1.65 & 8.89 & 15.35 & 0.17 & 7.36 & $<.001$ \\
\hline Age (years) & -0.27 & 0.07 & -0.41 & -0.13 & -0.10 & -3.75 & $<.001$ \\
\hline \multicolumn{8}{|l|}{ Marital status (ref.: married) } \\
\hline De facto & 2.16 & 2.16 & -2.08 & 6.39 & 0.03 & 1.00 & .317 \\
\hline Divorced/separated/widowed & 0.83 & 3.30 & -5.64 & 7.29 & 0.01 & 0.25 & .802 \\
\hline Single/never married & -2.29 & 1.92 & -6.05 & 1.48 & -0.03 & -1.19 & .234 \\
\hline \multicolumn{8}{|l|}{ Education (ref.: did not complete high school) } \\
\hline Year 12 or equivalent & -9.21 & 2.79 & -14.69 & -3.73 & -0.12 & -3.30 & .001 \\
\hline Trade, technical certificate, or diploma & -7.22 & 2.77 & -12.66 & -1.78 & -0.10 & -2.61 & .009 \\
\hline Undergraduate & -8.36 & 2.72 & -13.68 & -3.03 & -0.12 & -3.08 & .002 \\
\hline Postgraduate & -11.42 & 3.35 & -17.98 & -4.86 & -0.11 & -3.41 & .001 \\
\hline \multicolumn{8}{|l|}{ PGSI groups (ref.: non-problem) } \\
\hline Low risk & -8.31 & 2.47 & -13.16 & -3.46 & -0.09 & -3.36 & .001 \\
\hline Moderate risk & -2.46 & 2.50 & -7.35 & 2.44 & -0.03 & -0.98 & .325 \\
\hline Problem & -2.43 & 2.58 & -7.48 & 2.62 & -0.04 & -0.94 & .345 \\
\hline Exposure to marketing & -0.97 & 0.94 & -2.81 & 0.88 & -0.02 & -1.03 & .304 \\
\hline Average frequency of inducements used & -2.62 & 0.43 & -3.47 & -1.77 & -0.19 & -6.04 & $<.001$ \\
\hline Buying impulsiveness & 8.99 & 1.07 & 6.90 & 11.08 & 0.22 & 8.44 & $<.001$ \\
\hline
\end{tabular}

Note. Significant predictors are represented in bold. Unstd. coeff.: unstandardized coefficient; Std. coeff.: standardized coefficient; $S E$ : standard error; CI: confidence interval; LL: lower limit; UL: upper limit; PGSI: Problem Gambling Severity Index.

$R^{2}=.11,[F(15,1792)=15.40, p<.001]$.

Table 5. Regression coefficients predicting percentage of bets that were placed on impulse during the match

\begin{tabular}{|c|c|c|c|c|c|c|c|}
\hline \multirow[b]{2}{*}{ Predictor } & \multirow[b]{2}{*}{ Unstd. coeff. } & \multirow[b]{2}{*}{$S E$} & \multicolumn{2}{|c|}{$95 \% \mathrm{CI}$} & \multirow[b]{2}{*}{ Std. coeff. } & \multirow[b]{2}{*}{$t$} & \multirow[b]{2}{*}{$p$} \\
\hline & & & LL & UL & & & \\
\hline Intercept & -1.56 & 3.60 & -8.62 & 5.50 & & -0.43 & .664 \\
\hline Gender (ref:: male) & 1.23 & 0.93 & -0.59 & 3.05 & 0.03 & 1.33 & .185 \\
\hline Age (in years) & -0.12 & 0.04 & -0.20 & -0.04 & -0.08 & -3.02 & .003 \\
\hline \multicolumn{8}{|l|}{ Marital status (ref.: married) } \\
\hline De facto & -0.91 & 1.18 & -3.23 & 1.41 & -0.02 & -0.77 & .443 \\
\hline Divorced/separated/widowed & -0.13 & 1.86 & -3.77 & 3.51 & 0.00 & -0.07 & .945 \\
\hline Single/never married & -0.20 & 1.08 & -2.31 & 1.92 & -0.01 & -0.18 & .856 \\
\hline \multicolumn{8}{|l|}{ Education (ref.: did not complete high school) } \\
\hline Year 12 or equivalent & 2.44 & 1.53 & -0.55 & 5.44 & 0.05 & 1.60 & .110 \\
\hline A trade, technical certificate, or diploma & 1.75 & 1.52 & -1.22 & 4.72 & 0.04 & 1.16 & .248 \\
\hline Undergraduate & 3.27 & 1.50 & $\mathbf{0 . 3 3}$ & 6.22 & 0.08 & 2.18 & .029 \\
\hline Postgraduate & 4.21 & 1.88 & 0.52 & 7.89 & 0.07 & 2.24 & .025 \\
\hline Personal income & 0.05 & 0.12 & -0.18 & 0.29 & 0.01 & 0.45 & .654 \\
\hline Disposable income & -0.12 & 0.14 & -0.39 & 0.15 & -0.02 & -0.87 & .383 \\
\hline \multicolumn{8}{|l|}{ PGSI groups (ref.: non-problem) } \\
\hline Low risk & -0.51 & 1.36 & -3.18 & 2.16 & -0.01 & -0.38 & .707 \\
\hline Moderate risk & 0.75 & 1.37 & -1.94 & 3.45 & 0.02 & 0.55 & .583 \\
\hline Problem & 6.18 & 1.42 & 3.40 & 8.97 & 0.16 & 4.35 & $<.001$ \\
\hline Sports-betting frequency & -0.14 & 0.29 & -0.70 & 0.43 & -0.01 & -0.47 & .639 \\
\hline Sports-watching frequency & 1.92 & 0.44 & 1.06 & 2.79 & 0.14 & 4.37 & $<.001$ \\
\hline Exposure to marketing & -1.37 & 0.52 & -2.39 & -0.36 & -0.06 & -2.65 & .008 \\
\hline Average frequency of inducements used & 1.56 & 0.28 & 1.01 & 2.11 & 0.20 & 5.58 & $<.001$ \\
\hline Buying impulsiveness & 1.43 & 0.59 & 0.28 & 2.58 & 0.06 & 2.44 & .015 \\
\hline
\end{tabular}

Note. Significant predictors are represented in bold. Unstd. coeff.: unstandardized coefficient; Std. coeff.: standardized coefficient; $S E$ : standard error; CI: confidence interval; LL: lower limit; UL: upper limit; PGSI: Problem Gambling Severity Index.

$R^{2}=.25,[F(19,1701)=30.38, p<.001]$. 
$[F(19,1701)=30.38, p<.001]$. The following predictors were statistically significant when controlling for all other variables in the model: being younger, having an undergraduate or postgraduate qualification, being a problem gambler, more frequent sports watching, less-frequent exposure to marketing when exposed to the media, more frequent use of inducements, and higher buying impulsiveness (Table 5).

As data were missing for the personal income variable, we also ran this regression with personal income excluded. The overall results did not change.

\section{DISCUSSION}

This study has primarily focused on the potential role of wagering inducements in stimulating impulse sports betting. The regression analyses found that more frequent uptake of all types of wagering inducements predicted a more instantaneous, unplanned, and unreflective approach to betting through the placement of in-play bets. The results therefore support the hypothesis that more frequent users of sportsbetting inducements tend to bet more impulsively, but only in relation to impulse bets placed during (but not before) the match. These cross-sectional results cannot isolate causal pathways; however, other factors that were associated with impulse betting provide some possible explanations.

Problem gambling status was strongly associated with impulse betting during (and less strongly associated with impulse betting before) play, and more so, than uptake of inducements. This greater tendency to place in-play bets on impulse may reflect higher generalized impulsivity among this group, given that this trait is a defining feature of problem gambling (American Psychiatric Association, 2000), and a strong determinant of impulse purchasing in general (Amos, Holmes, \& Keneson, 2014). However, higher buying impulsiveness was a predictor of impulse betting both before and during play. This suggests that inplay betting per se is especially attractive to problem gamblers, over and above any effect of generalized buying impulsiveness. Prior research has also found that problem gamblers are particularly attracted to in-play betting, and that being able to bet during a match may contribute to gambling problems by offering frequent, repetitive gambling opportunities within a short timeframe (Braverman, LaPlante, Nelson, \& Shaffer, 2013; Hing et al., 2016; Hing, Vitartas, et al., 2017; McCormack \& Griffiths, 2013). The recent addition of cash-out options to in-play bets in many jurisdictions may also increase the potential for problem gambling, given decisions to cash out must necessarily be made impulsively and often in emotionally heightened contexts (Lopez-Gonzalez \& Griffiths, 2017a). Thus, even though problem gambling may independently predict in-play betting, the promotion of wagering inducements may further increase this behavior among problem gamblers by incentivizing and stimulating impulsive urges to bet. A review of gambling advertising research concluded that marketing cues have most impact on problem gamblers by providing reminders and triggers to gamble (Binde, 2014), and it is likely that wagering inducements have a similar effect while also providing financial incentives to act on these cues. This is consistent with Hanss et al. (2015) who found that problem gamblers were more likely to report that gambling advertising increased their involvement with gambling.

The finding that in-play betting per se is particularly attractive to problem gamblers also draws attention to how structural characteristics of betting products might lead to gambling problems. This issue has been comprehensively analyzed by McCormack and Griffiths (2013) in relation to the features of online gambling products, which may facilitate gambling behavior, including problematic gambling behavior, irrespective of the gambler's personal characteristics. Their analysis identified in-play betting as one such structural characteristic, because it facilitates within-session chasing and may increase perceptions of skill, leading to prolonged gambling. Our finding that wagering inducements, such as bonus bets, improved odds, and money-back guarantees, are associated with impulse betting during play also provides support for the role that structural features play in facilitating gambling and problem gambling (Lopez-Gonzalez et al., 2017a; McCormack \& Griffiths, 2013). These inducements were predictive of impulse betting during play, regardless of individual psychological characteristics, such as buying impulsiveness and sociodemographic characteristics such as age. Similar findings might also be expected for more recently introduced inducements, such as cash-out options, which also change the structural characteristics of the betting product (Lopez-Gonzalez \& Griffiths, 2017a).

Impulsive in-play betting was also associated with higher frequency of watching sport. This is not surprising for inplay betting on micro bets, as these betting opportunities arise only during the course of the event, and viewers need to be watching (or listening to) the event to be aware of these options. However, other bets that can be placed in-play (such as on the match outcome or more general in-match contingencies) can be promoted in advance of the match, as often occurs immediately before match broadcasts. Several studies have documented the proliferation of wagering advertising immediately before and during sporting matches, including promotions for inducements (Hing et al., 2015b; Milner et al., 2013; Sproston et al., 2015). Furthermore, a study examining the relative appeal of different message elements in wagering advertisements found that type of bet stimulated stronger betting intentions among all PGSI groups, compared with type of presenter, type of message format, and type of appeal, and that an incentivized bet was the most attractive bet type (Hing, Vitartas, et al., 2017). Thus, incentivized bets are particularly appealing in the marketplace, and viewers who watch more sport are more frequently exposed to their promotion, which may prompt their uptake during a match. However, frequency of watching sport was not associated with impulse betting before match commencement.

Surprisingly, however, respondents who reported lower incidence of seeing or hearing advertisements and promotions for sports betting when exposed to the media had a greater tendency to bet impulsively during play. One explanation for this unexpected finding is that higher-risk gamblers and those who favor impulse in-play bets may be less consciously aware of this promotion when it occurs. In Australia, the recent increase in wagering promotion has attracted substantial community criticism for being intrusive, annoying, and at saturation levels (Australian Communication and Media Authority, 2013; Sproston et al., 2015). Focus 
group research has suggested that viewers with low involvement in sports betting are more opposed to this promotion than more highly involved bettors (Lamont et al., 2016); they may therefore notice this activity more, because they find it irritating, distracting, and of no or little value to them. However, further research is required to clarify this contention.

The regression results also indicated that impulse betting both before and after match commencement was more frequent among younger sports bettors. Young men in particular predominate among sports bettors (Humphreys \& Pérez, 2012; Wood \& Williams, 2011) and are the target market for sports-betting advertising, including promotions for incentivized bets during play. Sproston et al. (2015) describe how themes in sports-betting promotions center on male bonding, attractiveness to women, power and control, and commonly depict successful sports bettors as educated, savvied, professional young men. Lopez-Gonzalez, Guerrero-Solé, et al. (2017) note that advertising typically presents sports betting as a male-dominated and individualized consumption practice, and that it frequently depicts inplay betting, betting in emotionally charged situations, and the staking of small amounts for large returns, implying high-risk bets. It appears that this marketing is effectively targeted and may contribute to the spontaneous uptake of impulse in-play betting among this demographic group (particularly those who are more highly educated), especially given that younger adults are known to be more impulsive and vulnerable to advertising, compared with their older counterparts (Pechmann, Levine, Loughlin, \& Leslie, 2005).

Of interest is that female sports bettors were more likely than their male counterparts to bet on impulse before a match. They were also less likely to research and plan their bets in advance. Young women are a recently emergent market for sports betting, and this result may provide some preliminary evidence on the existence of certain unique behavioral patterns within this market group. While women are less likely than men to participate in sports betting (LaPlante, Schumann, LaBrie, \& Shaffer, 2008), women are increasingly participating in online gambling due to the greater anonymity, safety, and opportunities for practice and learning that it allows, along with lower levels of stigma and intimidation (McCormack, Shorter, \& Griffiths, 2014). However, while gender differences have been observed in online gambling preferences and motivations, little is known about any gender differences in sports betting or online gambling patterns (McCormack et al., 2014). One study utilizing real sports-betting data from a wagering operator found that, for both fixed-odds and live-action betting, women bet for a shorter time period, bet on more days, made significantly larger bets but had lower net losses compared with male account holders (LaBrie, LaPlante, Nelson, Schumann, \& Shaffer, 2007). In contrast, McCormack et al. (2014) found that women were less likely than men to be regular online sports bettors. Given the apparent increase in female sports bettors and the paucity of related knowledge, this is a fruitful area for future research.

A key limitation of this study is its inability to identify causal effects, and alternative methodologies are required to clarify the direction of associations found here. Other limitations include the convenience sample, which was overrepresentative of problem gamblers, but which therefore enabled key analyses to be conducted. Nevertheless, absolute values such as frequencies should be interpreted with caution. The survey relied on self-report, and responses may have been affected by recall lapses and biases. The findings are also restricted to Australian sports bettors, and results may vary in different countries due to variations in jurisdictional requirements, sports-betting products, and inducements, advertising and promotions, and sports bettor characteristics. Additional research is required to confirm our results and to add to the sparse knowledge that currently exists about sports betting, wagering inducements, in-play betting, and gambling on impulse.

\section{CONCLUSIONS}

This study found that a tendency to place impulse bets during sporting events was predicted by more frequent uptake of wagering inducements, problem gambling status, higher buying impulsiveness, higher frequency of watching sports, younger age, and higher educational status among a large sample of Australian sports bettors. While uptake of wagering inducements independently predicted impulse betting during sporting matches, it appeared to be particularly effective in stimulating this behavior among problem gamblers and frequent sports viewers. Sports bettors with a greater tendency to place impulse bets before match commencement also tended to have higher buying impulsiveness and to be younger, but they used inducements less frequently, and tended to be female, less-educated and nonproblem, moderate-risk or problem gamblers, but not lowrisk gamblers.

Betting on impulse should be discouraged, because it reflects uninformed decision-making, impaired control, and betting more than planned, thereby undermining responsible consumption of gambling. The ability to place bets in-play facilitates betting on impulse, yet opportunities for in-play betting have increased in many jurisdictions with industry deregulation and the growth of professional sporting events, betting markets, and access to Internet and mobile-betting platforms. Policy-makers should take a cautious approach to deregulating in-play betting, given its association with impulse betting and problem gambling, especially among young adults.

The uptake of wagering inducements is also associated with impulse betting during sporting events, which suggests that their provision and marketing should be contained. Their heavy promotion during sporting events themselves, push marketing activity directly to consumers, and ease of uptake at the point-of-sale mean that wagering inducements are likely to provide strong cues that trigger unreflective gambling among young, impulsive bettors who may already have an existing gambling problem. Reducing gambling harm and preventing current and future gambling problems among today's young adults are likely to require further regulatory restraints on incentivizing betting on impulse.

Funding sources: Financial support for this study was received from Southern Cross University when $\mathrm{NH}$ and AR were previously employed there. 
Authors' contribution: All authors designed the study and wrote the protocol. NH conducted literature searches and wrote the first draft of the manuscript. AR conducted the statistical analysis. EL and PV reviewed and helped to refine all research materials. All authors contributed to and have approved the final manuscript. The corresponding author affirms that she had access to all data from the study, both what is reported and what is unreported, and also that she had complete freedom to direct its analysis and its reporting, without influence from any sponsors. She also affirms that there was no editorial direction or censorship from any sponsors.

Conflict of interest: NH has received gambling research grants from Gambling Research Australia, the Queensland Government, NSW Government, South Australian Government, Victorian Government, Victorian Responsible Gambling Foundation, the Australian Communications and Media Authority, the Australian National Research Organization for Women's Safety, and the Alberta Gambling Research Institute. She has conducted unpublished consultancy work for Echo Entertainment, Singapore Pools and Sportsbet. AR has received gambling research grants from Gambling Research Australia, the Queensland Government, Victorian Responsible Gambling Foundation, the Australian Communications and Media Authority, the National Association for Gambling Studies, and the Alberta Gambling Research Institute. He has conducted unpublished consultancy work for Echo Entertainment. EL has received gambling research grants from the Australian Government Department of Families, Housing, Community Services and Indigenous Affairs, Gambling Research Australia, and the Victorian Responsible Gambling Foundation. PV has received gambling research grants from the Queensland Government. The authors report no financial or other relationship relevant to the subject of this article.

\section{REFERENCES}

American Psychiatric Association. (2000). Diagnostic and statistical manual of mental disorders (4th ed.). Washington, DC: American Psychiatric Association.

Amos, C., Holmes, G. R., \& Keneson, W. C. (2014). A metaanalysis of consumer impulse buying. Journal of Retailing and Consumer Services, 21(2), 86-97. doi:10.1016/j.jretconser. 2013.11.004

Australian Communication and Media Authority. (2013). Betting odds and advertising for betting agencies during sports broadcasts: Community research. Canberra, Australia: Australian Communication and Media Authority.

Binde, P. (2014). Gambling advertising: A critical research review. London: Responsible Gambling Trust.

Braverman, J., LaPlante, D. A., Nelson, S. E., \& Shaffer, H. J. (2013). Using cross-game behavioral markers for early identification of high-risk Internet gamblers. Psychology of Addictive Behaviors, 27(3), 868-877. doi:10.1037/a003 2818

Calado, F., \& Griffiths, M. D. (2016). Problem gambling worldwide: An update and systematic review of empirical research
(2000-2015). Journal of Behavioral Addictions, 5(4), 592613. doi:10.1556/2006.5.2016.073

Carter, O. B., Mills, B. W., \& Donovan, R. J. (2009). The effect of retail cigarette pack displays on unplanned purchases: Results from immediate postpurchase interviews. Tobacco Control, 18(3), 218-221. doi:10.1136/tc.2008.027870

Danson, A. (2010). Sponsorship by gambling companies in the UK and Europe: The opportunities and challenges. Journal of Sponsorship, 3(2), 194-201.

Dawson, S., \& Kim, M. (2010). Cues on apparel web sites that trigger impulse purchases. Journal of Fashion Marketing and Management: An International Journal, 14(2), 230-246. doi:10.1108/13612021011046084

Drossos, D. A., Kokkinaki, F., Giaglis, G. M., \& Fouskas, K. G. (2014). The effects of product involvement and impulse buying on purchase intentions in mobile text advertising. Electronic Commerce Research and Applications, 13(6), 423-430. doi:10.1016/j.elerap.2014.08.003

Ferris, J., \& Wynne, H. (2001). The Canadian Problem Gambling Index. Ottawa, ON: Canadian Centre on Substance Abuse.

Goldstein, A. L., Vilhena-Churchill, N., Stewart, S. H., Hoaken, P. N., \& Flett, G. L. (2016). Mood, motives, and money: An examination of factors that differentiate online and non-online young adult gamblers. Journal of Behavioral Addictions, 5(1), 68-76. doi:10.1556/2006.5.2016.003

Griffiths, M. (2007). Mobile phone gambling. In D. Taniar (Ed.), Encyclopaedia of mobile computing and commerce (pp. 553-556). Hershey, PA: Information Science Reference.

Guerrero-Solé, F., Lopez-Gonzalez, H., \& Griffiths, M.D. (2017). Online gambling advertising and the third-person effect: A pilot study. International Journal of Cyber Behavior, Psychology and Learning, 7(2), 15-30. doi:10.4018/IJCBPL.2017040102

Hanss, D., Mentzoni, R. A., Griffiths, M. D., \& Pallesen, S. (2015). The impact of gambling advertising: Problem gamblers report stronger impacts on involvement, knowledge, and awareness than recreational gamblers. Psychology of Addictive Behaviors, 29(2), 483-491. doi:10.1037/adb0000062

Hing, N., Cherney, L., Blaszczynski, A., Gainsbury, S., \& Lubman, D. (2014). Do advertising and promotions for online gambling increase gambling consumption? An exploratory study. International Gambling Studies, 14(3), 394-409. doi:10.1080/14459795.2014.903989

Hing, N., Gainsbury, S., Blaszczynski, A., Wood, R., Lubman, D., \& Russell, A. (2014). Interactive gambling. Melbourne, VIC: Gambling Research Australia.

Hing, N., Lamont, M., Vitartas, P., \& Fink, E. (2015a). How sports bettors respond to sports-embedded gambling promotions: Implications for compulsive consumption. Journal of Business Research, 68(10), 2057-2066. doi:10.1016/j.jbusres. 2015.03.003

Hing, N., Lamont, M., Vitartas, P., \& Fink, E. (2015b). Sportsembedded gambling promotions: A study of exposure, sports betting intention and problem gambling amongst adults. International Journal of Mental Health and Addiction, 13(1), 115-135. doi:10.1007/s11469-014-9519-9

Hing, N., Li, E., Vitartas, P., \& Russell, A. M. T. (2017). On the spur of the moment: Intrinsic predictors of impulse sports betting. Journal of Gambling Studies. Advance online publication. doi:10.1007/s10899-017-9719-x

Hing, N., Russell, A. M. T., Vitartas, P., \& Lamont, M. (2016). Demographic, behavioural and normative risk factors for 
gambling problems amongst sports bettors. Journal of Gambling Studies, 32(2), 625-641. doi:10.1007/s10899015-9571-9

Hing, N., Sproston, K., Brading, R., \& Brook, K. (2015). Review and analysis of sports and race betting inducements. Melbourne, VIC: Victorian Responsible Gambling Foundation.

Hing, N., Sproston, K., Brook, K., \& Brading, R. (2017). The structural features of sports and race betting inducements: Issues for harm minimisation and consumer protection. Journal of Gambling Studies, 33(2), 685-704. doi:10.1007/s10899016-9642-6

Hing, N., Vitartas, P., \& Lamont, M. (2017). Understanding persuasive attributes of sports betting advertisements: A conjoint analysis of selected elements. Journal of Behavioral Addictions, 6(4), 658-668. doi:10.1556/2006.6.2017.062

Hing, N., Vitartas, P., Lamont, M., \& Fink, E. (2014). Adolescent exposure to gambling promotions during televised sport: An exploratory study of links with gambling intentions. International Gambling Studies, 14(3), 374-393. doi:10. 1080/14459795.2014.902489

Humphreys, B. R., \& Pérez, L. (2012). Who bets on sports? Characteristics of sports bettors and the consequences of expanding sports betting opportunities. Estudios de economía aplicada, 30(2), 579-597.

Jeffrey, S. A., \& Hodge, R. (2007). Factors influencing impulse buying during an online purchase. Electronic Commerce Research, 7(3-4), 367-379. doi:10.1007/s10660-007-9011-8

Jones, S. C., \& Smith, K. M. (2011). The effect of point of sale promotions on the alcohol purchasing behaviour of young people in metropolitan, regional and rural Australia. Journal of Youth Studies, 14(8), 885-900. doi:10.1080/13676261. 2011.609538

Kannan, P. K., Chang, A.-M., \& Whinston, A. B. (2001). Wireless commerce: Marketing issues and possibilities. In Proceedings of the 34th Hawaii international conference on system sciences. Los Alamitos, Hawaii: IEEE Computer Society Press.

Kirchner, T. R., Cantrell, J., Anesetti-Rothermel, A., Ganz, O., Vallone, D. M., \& Abrams, D. B. (2013). Geospatial exposure to point-of-sale tobacco: Real-time craving and smokingcessation outcomes. American Journal of Preventive Medicine, 45(4), 379-385. doi:10.1016/j.amepre.2013.05.016

Koski, N. (2004). Impulse buying on the Internet: Encouraging and discouraging factors. Frontiers of E-business Research, 4, 23-35.

LaBrie, R. A., LaPlante, D. A., Nelson, S. E., Schumann, A., \& Shaffer, H. J. (2007). Assessing the playing field: A prospective longitudinal study of Internet sports gambling behavior. Journal of Gambling Studies, 23(3), 347-362. doi:10.1007/ s10899-007-9067-3

Lamont, M., Hing, N., \& Vitartas, P. (2016). Affective responses to gambling promotions during televised sport: A qualitative analysis. Sport Management Review, 19(3), 319-331. doi:10. 1016/j.smr.2015.06.002

LaPlante, D. A., Schumann, A., LaBrie, R. A., \& Shaffer, H. J. (2008). Population trends in Internet sports gambling. Computers in Human Behavior, 24(5), 2399-2414. doi:10. 1016/j.chb.2008.02.015

Lopez-Fernandez, O., Kuss, D. J., Romo, L., Morvan, Y., Kern, L., Graziani, P., Rousseau, A., Rumpf, H. J., Bischof, A., Gässler, A. K., Schimmenti, A., Passanisi, A., Männikkö, N.,
Kääriänen, M., Demetrovics, Z., Király, O., Chóliz, M., Zacarés, J. J., Serra, E., Griffiths, M. D., Pontes, H. M., Lelonek-Kuleta, B., Chwaszcz, J., Zullino, D., Rochat, L., Achab, S., \& Billieux, J. (2017). Self-reported dependence on mobile phones in young adults: A European cross-cultural empirical survey. Journal of Behavioral Addictions, 6(2), 168 177. doi:10.1556/2006.6.2017.020

Lopez-Gonzalez, H., \& Griffiths, M. D. (2016). Understanding the convergence of online sports betting markets. International Review for the Sociology of Sport, 1-17. doi:10.1177/10126 90216680602

Lopez-Gonzalez, H., \& Griffiths, M. D. (2017a). Cashing out in sports betting: Implications for problem gambling and regulation. Gaming Law Review, 21(4), 323-326. doi:10.1089/ glr2.2017.2144

Lopez-Gonzalez, H., \& Griffiths, M. D. (2017b). Betting, forex trading, and fantasy gaming sponsorships: A responsible marketing inquiry into the 'gamblification' of English football. International Journal of Mental Health and Addiction. Advance online publication. doi:10.1007/s11469-017-9788-1

Lopez-Gonzalez, H., Estévez, A., \& Griffiths, M. D. (2017a). Marketing and advertising online sports betting: A problem gambling perspective. Journal of Sport and Social Issues, 41(3), 256-272. doi:10.1177/0193723517705545

Lopez-Gonzalez, H., Estévez, A., \& Griffiths, M. D. (2017b). Controlling the illusion of control: A grounded theory of sports betting advertising in the UK. International Gambling Studies, 18(1), 39-55. doi:10.1080/14459795.2017. 1377747.

Lopez-Gonzalez, H., Guerrero-Solé, F., Estévez, A., \& Griffiths, M. (2017). Betting is loving and bettors are predators: A conceptual metaphor approach to online sports betting advertising. Journal of Gambling Studies. Advance online publication. doi:10.1007/s10899-017-9727-x

Lopez-Gonzalez, H., Guerrero-Solé, F., \& Griffiths, M. D. (2017). A content analysis of how 'normal' sports betting behaviour is represented in gambling advertising. Addiction Research \& Theory. Advance online publication. doi:10.1080/16066359. 2017.1353082

Martin, I. M., Kamins, M. A., Pirouz, D. M., Davis, S. W., Haws, K. L., Mirabito, A. M., Mukherjee, S., Rapp, J. M., \& Grover, A. (2013). On the road to addiction: The facilitative and preventive roles of marketing cues. Journal of Business Research, 66(8), 1219-1226. doi:10.1016/j.jbusres.2012.08.015

McCormack, A., \& Griffiths, M. D. (2013). A scoping study of the structural and situational characteristics of Internet gambling. International Journal of Cyber Behavior, Psychology and Learning (IJCBPL), 3(1), 29-49. doi:10.4018/ijcbpl.2013010104

McCormack, A., Shorter, G., \& Griffiths, M. D. (2014). An empirical study of gender differences in online gambling. Journal of Gambling Studies, 30(1), 71-88. doi:10.1007/ s10899-012-9341-x

Milner, L., Hing, N., Vitartas, P., \& Lamont, M. (2013). An exploratory study of embedded gambling promotion in Australian football television broadcasts. Communication, Politics and Culture, 46, 177-198.

Newall, P. W. (2015). How bookies make your money. Judgment and Decision Making, 10(3), 225.

Newall, P. W. (2017). Behavioral complexity of British gambling advertising. Addiction Research \& Theory, 25(6), 505-511. doi:10.1080/16066359.2017.1287901 
Pechmann, C., Levine, L., Loughlin, S., \& Leslie, F. (2005). Impulsive and self-conscious: Adolescents' vulnerability to advertising and promotion. Journal of Public Policy and Marketing, 24(2), 202-221. doi:10.1509/jppm.2005.24. 2.202

Pettigrew, S., Biagioni, N., Jones, S. C., Daube, M., Kirby, G., Stafford, J., \& Chikritzhs, T. (2015). Sales promotion strategies and youth drinking in Australia. Social Science \& Medicine, 141, 115-122. doi:10.1016/j.socscimed.2015.07.035

Rook, D. W., \& Fisher, R. J. (1995). Normative influences on impulsive buying behavior. Journal of Consumer Research, 22(3), 305-313. doi:10.1086/209452

Sproston, K., Hanley, C., Brook, K., Hing, N., \& Gainsbury, S. (2015). Marketing of sports betting and racing. Melbourne, VIC: Gambling Research Australia.
Unni, R., \& Harmon, R. (2007). Perceived effectiveness of push vs. pull mobile location based advertising. Journal of Interactive Advertising, 7(2), 28-40. doi:10.1080/15252019.2007. 10722129

Wakefield, M., Germain, D., \& Henriksen, L. (2008). The effect of retail cigarette pack displays on impulse purchase. Addiction, 103(2), 322-328. doi:10.1111/j.1360-0443.2007.02062.x

Wood, R. T., \& Williams, R. J. (2011). A comparative profile of the Internet gambler: Demographic characteristics, gameplay patterns, and problem gambling status. New Media \& Society, 13(7), 1123-1141. doi:10.1177/1461444810397650

Xu, Y., \& Huang, J. S. (2014). Effects of price discounts and bonus packs on online impulse buying. Social Behavior and Personality: An International Journal, 42(8), 1293-1302. doi:10.2224/sbp.2014.42.8.1293 